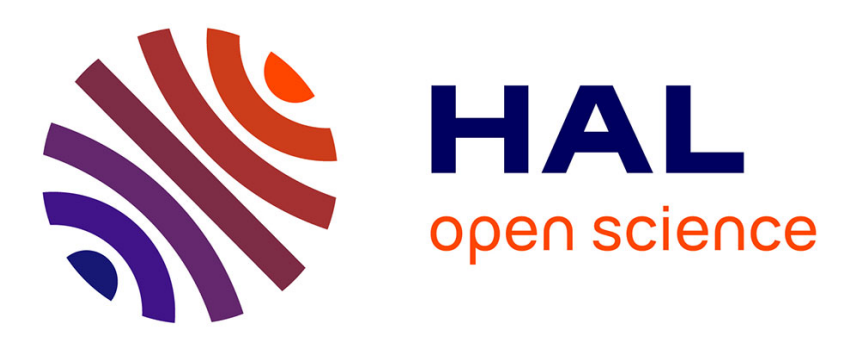

\title{
The Stationary-Gaze Task Should Not Be Systematically Used as the Control Task in Studies of Postural Control
}

\author{
Cédrick T. Bonnet, Sébastien Szaffarczyk
}

\section{To cite this version:}

Cédrick T. Bonnet, Sébastien Szaffarczyk. The Stationary-Gaze Task Should Not Be Systematically Used as the Control Task in Studies of Postural Control. Journal of Motor Behavior, 2016, Journal of Motor Behavior, 49, pp.494-504. 10.1080/00222895.2016.1241749 . hal-02186732v2

\section{HAL Id: hal-02186732 \\ https://hal.univ-lille.fr/hal-02186732v2}

Submitted on 10 Aug 2021

HAL is a multi-disciplinary open access archive for the deposit and dissemination of scientific research documents, whether they are published or not. The documents may come from teaching and research institutions in France or abroad, or from public or private research centers.
L'archive ouverte pluridisciplinaire HAL, est destinée au dépôt et à la diffusion de documents scientifiques de niveau recherche, publiés ou non, émanant des établissements d'enseignement et de recherche français ou étrangers, des laboratoires publics ou privés. 


\section{The Stationary-Gaze Task Should Not Be Systematically Used as the Control Task in Studies of Postural Control}

Cédrick T. Bonnet and Sébastien Szaffarczyk

\section{QUERY SHEET}

This page lists questions we have about your paper. The numbers displayed at left can be found in the text of the paper for reference. In addition, please review your paper as a whole for correctness.

Q1. Au: Please provide reference for citation [Swan et al., 2003].

Q2. Au: Please mention panel C in the Figure 2 caption.

Q3. Au: Please provide an English translation of the title for Cegarra and Morgado.

Q4. Au: Please provide an English translation of the title for Rougier and Garin.

\section{TABLE OF CONTENTS LISTING}

The table of contents for the journal will list your paper exactly as it appears below:

The Stationary-Gaze Task Should Not Be Systematically Used as the Control Task in Studies of Postural Control Cédrick T. Bonnet and Sébastien Szaffarczyk 


\title{
The Stationary-Gaze Task Should Not Be Systematically Used as the Control Task in Studies of Postural Control
}

\author{
Cédrick T. Bonnet, Sébastien Szaffarczyk \\ SCALab, Laboratoire de Neurosciences Fonctionnelles et Pathologies, CNRS UMR 9193, University of Lille 2, France.
}

5 ABSTRACT. In studies of postural control, a control task is often used to understand significant effects obtained with experimental manipulations. This task should be the easiest task and (therefore) engage the lowest behavioral variability and cognitive workload. Since 1983, the stationary-gaze task is considered as the most rele-

10 vant control task. Instead, the authors expected that free looking at small targets (white paper or images; visual angle: $12^{\circ}$ ) could be easier tasks. To verify this assumption, 16 young individuals performed stationary-gaze, white-panel, and free-viewing $12^{\circ}$ tasks in steady and relaxed stances. The stationary-gaze task led to sig-

15 nificantly higher cognitive workload (mean score in the National Aeronotics and Space Administration Task Load Index questionnaire), higher interindividual body (head, neck, and lower back) linear variability, and higher interindividual body angular variability-not systematically yet-than both other tasks. There was

20 more cognitive workload in steady than relaxed stances. The authors also tested if a free-viewing $24^{\circ}$ task could lead to greater angular displacement, and hence greater body sway, than could the other tasks in relaxed stance. Unexpectedly, the participants mostly moved their eyes and not their body in this task. In the dis-

25 cussion, the authors explain why the stationary-gaze task may not be an ideal control task and how to choose this neutral task.

Keywords: cognitive workload, control task, postural control, precise visual tasks, stationary-gaze task, young adults

n the literature on postural control, some experimenters are interested in the effect of visual tasks on postural control and how the central nervous system (CNS) can simultaneously control upright stance and oculomotor behaviors to perform visual tasks. In these studies, investigators usually study how precise (fast and accurate) visual tasks can influ-

35 ence the way individuals sway. Many kinds of precise visual tasks have been used, such as tracking a dot appearing alternatively left and right at a constant angle and frequency (Giveans, Yoshida, Bardy, Riley, \& Stoffregen, 2011; Rodriguez et al., 2013; Rougier \& Garin, 2007; Stof-

40 fregen, Bardy, Bonnet, Hove, \& Oullier, 2007; Stoffregen, Bardy, Bonnet, \& Pagulayan, 2006), counting the occurrence of a letter in a text (Bonnet, Kinsella-Shaw et al., 2010; Prado, Duarte, \& Stoffregen, 2007; Stoffregen, Pagulayan, Bardy, \& Hettinger, 2000), detecting one or several

45 target(s) in a visual display (Shockley, Santana, \& Fowler, 2003), aligning two crosses (Mitra, Knight, \& Munn, 2013), detecting a difference between two targets (Stoffregen, Hove, Bardy, Riley, \& Bonnet, 2007b), and recognizing a target displayed only several milliseconds (Poulain \&

50 Giraudet, 2008). All these precise visual tasks are known to significantly influence postural control (e.g., Bonnet, Kinsella-Shaw et al., 2010; Mitra et al., 2013; Poulain \& Giraudet, 2008; Prado et al., 2007; Rougier \& Garin, 2007; Stoffregen et al., 2000; Stoffregen et al., 2006; Stoffregen,
Bardy et al., 2007; Stoffregen, Hove et al., 2007). They are the experimental tasks of interest.

When experimenters search to discover the effect of precise visual tasks on postural control, they usually record upright stance in a control task to provide baseline data. Baseline data are required both to show the existence of significant effects caused by the experimental manipulations and to know the direction of these effects. It is definitely important to use an appropriate control task to well understand the effects of the experimental manipulations (Fraizer $\&$ Mitra, 2008). The control task should depend on-or be adjusted to - the experimental tasks of interest, both control and experimental tasks being linked to each other.

In 1983, a consortium of specialists discussed the definition and criteria of this control task (Kapteyn et al., 1983). They argued that this task should lead to the minimum amount of variability of postural behavior. Indeed, a task engaging low variability could be the most reproducible task and thus allow comparisons of results within and between studies (Kapteyn et al., 1983). Moreover, analyses between the control and experimental tasks could more easily lead to significant findings if individuals exhibit lower behavioral variability in the control task. The consortium decided that the most relevant control task should be the stationary-gaze task. In this task, participants stare at a stationary target (dot, cross, or circular area) throughout the trial (Kapteyn et al., 1983).

A few years later, researchers acknowledged that postural control can involve higher structures of the CNS (Mihara, Miyai, Hatakenaka, Kubota, \& Sakoda, 2008; Teasdale, Bard, LaRue, \& Fleury, 1993; Woollacott, Shumway-Cook, \& Nashner, 1986). Hence, since 1985, it can be assumed that different experimental tasks may alter the cognitive demand. Therefore, and to complete Kapteyn et al.'s (1983) definition, the control task should also require the minimum amount of cognitive workload, it should not induce any interference (Swan, Otani, Loubert, Sheffert, \& Dunbar, 2004), and it should be a single task (Swan et al., 2004) or the easiest task (Mitra, 2003). In contrast, the experimental dual tasks should be harder and induce interference (Swan et al., 2003).

In the present manuscript, we questioned whether the stationary-gaze task should systematically be considered as the gold control task. We questioned whether this task was

Correspondence address: Cédrick T. Bonnet, SCALab, Laboratoire de Neurosciences Fonctionnelles et Pathologies, CNRS UMR 9193, University of Lille 2, Lille, France. e-mail: cedrick. bonnet@chru-lille.fr. 
the easiest task requiring the lowest variability in posture

100 and the lowest cognitive workload. We had some doubt about it because this stationary-gaze task was already assumed as cognitively demanding (Ajrezzo, WienerVacher \& Bucci, 2013; Ben Hamed, Duhamel, Bremmer, \& Graf, 2002), as a difficult (Wade, 2010) and tiring task

105 (Rougier \& Garin, 2006).

The white-panel task has also been used as a control task in the literature reports (e.g., Bonnet, Kinsella-Shaw et al., 2010; Prado et al., 2007; Stoffregen et al., 2000). In this task, participants simply look at a small white panel. In

110 these studies, the white panel was projected within a small visual angle (i.e., on a visual angle lower than $15^{\circ}$ delimited by a circle with a black line) to allow participants to look at the target in moving (rotating) only their eyes and not their head or body (Hallett, 1986). This task may be less cogni-

115 tively demanding than the stationary-gaze task because it does not impose any constraint on fixation or attention (Ben Hamed et al., 2002). Similarly, when participants simply perform free exploration of a small image (lower than $15^{\circ}$ ), the visual task may not be cognitively demanding

120 because fixations and saccades are simply exploratory, individuals can look at the image with no goal. Moreover, if participants do not move any body part to perform the visual task, but only their eyes, they may not engage greater behavioral variability than in the stationary-gaze task.

125 Hence, these free-looking tasks may also be relevant control tasks. In other words, we suggest that free looking could stand as a potentially control, single, tasks and not as precise or experimental tasks.

The study's primary objective was to test whether white-

130 panel and/or free-viewing $12^{\circ}$ tasks could be easier tasks and thus lead to lower cognitive workload and lower variability of postural sway than the stationary-gaze task. We assumed that the stationary-gaze task should lead to higher cognitive workload than these other tasks. As a conse-

135 quence, we assumed that the stationary-gaze task would lead to higher variability of postural sway. A secondary objective was to test whether a free-viewing $24^{\circ}$ task would lead the participants to rotate their head and, therefore, move their body significantly more than in the three other

140 tasks. The general goal of the present manuscript was methodological; we did not test any model of postural control.

\section{METHODS}

\section{Participants}

Sixteen healthy young students (eight men, eight women)

145 from the Universities of Lille volunteered to participate in this study. The mean age, bodyweight and height of the participants were $20.5 \pm 0.89$ years, $66 \pm 15.74 \mathrm{~kg}$, and $172.19 \mathrm{~m} \pm 10.13$, respectively. The study was approved by the local ethical committee of our laboratory and per-

150 formed in accordance with the tenets of the Declaration of
Helsinki. The participants gave their written informed consent to participation.

\section{Apparatus}

A dual-top force platform (AMTI, Watertown, MA) was used to record center of pressure (COP) displacement with a sampling frequency of $120 \mathrm{~Hz}$. The platform was placed $2.75 \mathrm{~m}$ from the facing wall. A magnetic tracking system (Polhemus Liberty 240/8-8 System, Colchester, VT) was used to record head, neck and lower back marker displacements with a sampling frequency of $120 \mathrm{~Hz}$. The markers were positioned at the occiput (head marker, on the headset), at the seventh cervical vertebra (neck marker), and at the fifth lumbar vertebra (lower back marker, on a chest belt). A head-mounted eye tracker (SensoMotoric Instruments, Teltow, Germany) was used to record eye motions. The iViewX system recorded the pupil position at a sampling rate of $50 \mathrm{~Hz}$. These three apparatuses were synchronized all together with the projection of the experimental images.

A validated French version of the National Aeronotics and Space Administration Task Load Index (NASA-TLX; Cegarra \& Morgado, 2009) was used to quantify the cognitive workload. This multidimensional questionnaire was chosen because it has excellent reliability, sensitivity and utility (Hart, 2006) and because it is sensitive to fine variations between tasks (Cegarra \& Morgado, 2009). This questionnaire was used to measure a global variable of the cognitive workload.

During recordings, the participants had their feet on the printed lines that marked the normative stance width and angle recommended by McIlroy \& Maki (1997; $17 \mathrm{~cm}$ and $\left.14^{\circ}\right)$.

The eight images projected to the participants displayed scenes of real life such as parts of a town (streets, crowds) and various rooms from houses. The content of all images were as neutral as possible to avoid emotional images to potentially impact postural control (Stins \& Beek, 2007). Each trial showed a different image.

\section{Tasks}

The study consisted of eight experimental tasks, each of which performed with two trials (each lasting $45 \mathrm{sec}$ ). The eight tasks were run successively in a random order but the two trials in each task were performed one after another in each task. The four visual tasks were the stationary-gaze, white-panel, and free-viewing $12^{\circ}$ and $24^{\circ}$ tasks (Figures $1 \mathrm{~A}, 1 \mathrm{~B}, 1 \mathrm{C}$, and 1D, respectively). These tasks were performed with the participants told to stand as steadily as possible (steady instruction) or to adopt a relaxed stance. The participants were also told to refrain from making any voluntary movement unrelated to the task performed (e.g., hand movements). Both types of instruction (steady and 

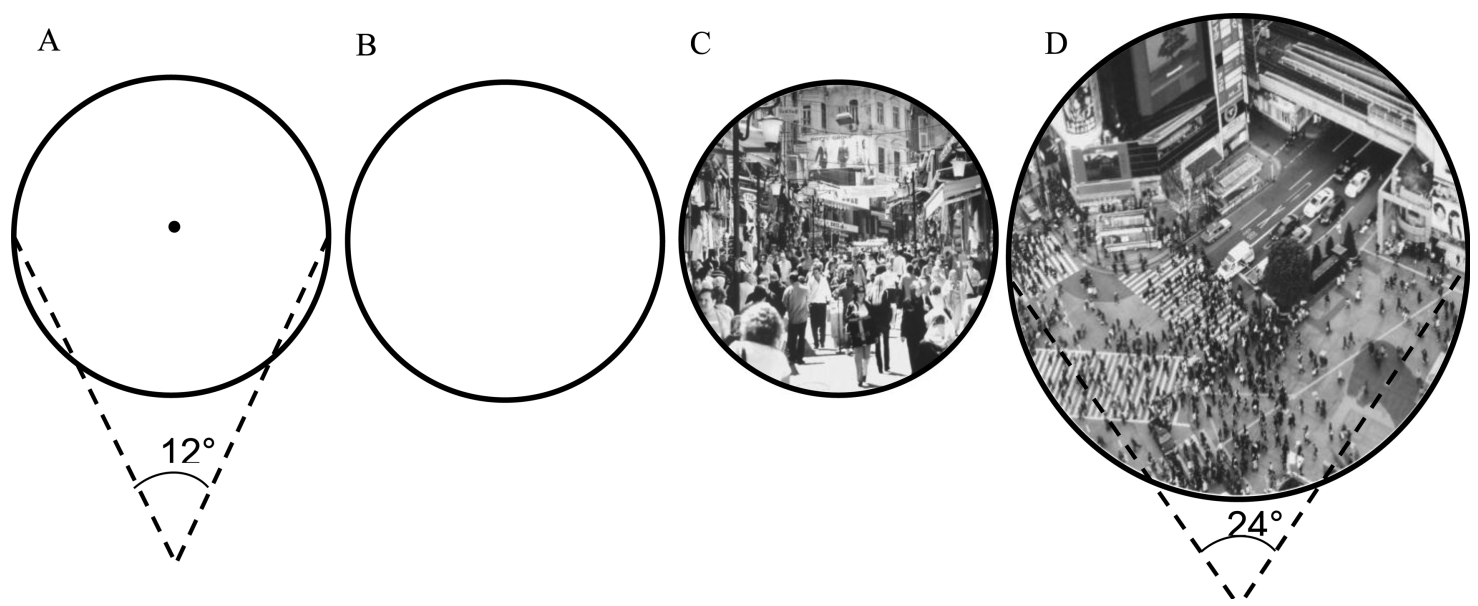

FIGURE 1. (A) Stationary-gaze task: the participants had to stare at the black dot $\left(1^{\circ}\right.$ of visual angle) throughout the full trial. (B) White-panel task: the participants first stared at the black dot (as in panel A) $5 \mathrm{~s}$ and then looked at the white panel within the circle $40 \mathrm{~s}\left(12^{\circ}\right.$ of visual angle); (C) Free-viewing $12^{\circ}$ : the participants first stared at the black dot $5 \mathrm{~s}$ (dot surrounded by the image) and then freely explored the image within the circle $40 \mathrm{~s}\left(12^{\circ}\right.$ of visual angle). (D) Free-viewing $24^{\circ}$ : the participants first stared at the black dot $5 \mathrm{~s}$ (dot surrounded by the image) and then freely explored the image within the circle $40 \mathrm{~s}\left(24^{\circ}\right.$ of visual angle). The images are not on scale. The images were shown in color, not in black and white as shown in Figure 1.

relaxed) were used to test if the findings could be generalized in both contexts.

In the stationary-gaze task (Figure 1A), the participants had

ate at a black dot of $1^{\circ}$ projected at eye height and surrounded by a black circle line of $12^{\circ}$. The white-panel task was similar to the stationary-gaze task for the first $5 \mathrm{~s}$. Then, the central black dot disappeared and the participants could freely look anywhere they like within the circle (Figure 1B). In the

210 free-viewing $12^{\circ}$ and $24^{\circ}$ tasks, the participants first had to stare at a black dot $\left(1^{\circ}\right)$ surrounded by an image for $5 \mathrm{~s}$. Then, the dot disappeared and they could freely look at the image within the circle (Figures 1C and 1D).

In the free-viewing $12^{\circ}$ and $24^{\circ}$ tasks, the images were

215 different (e.g., Figures 1C and 1D). To control the image effect on postural and oculomotor behaviors, half of the participants looked at images $1-4$ in the free-viewing $12^{\circ}$ task and images 5-8 in the free-viewing $24^{\circ}$ task and the other half looked at images 5-8 in the free-viewing $12^{\circ}$

220 task and images 1-4 in the free-viewing $24^{\circ}$ task. In both free-viewing tasks, the participants were invited not to search anything in the image but to look at it freely. After the completion of each free-viewing task, the participants were questioned to check that none of them performed any

225 searching task. Indeed, we needed to control whether the participants did not perform an experimental task as we defined it in our introduction.

The participants performed the tasks barefoot. The light was turned off so that the participants could clearly see the

230 image. The eight tasks were run by block of two trials in order to evaluate the cognitive workload after each task (based on two successive trials). The images were projected further than $1.5 \mathrm{~m}$ to avoid images to provide any useful information for postural control (Bonnet, Temprado, \& Berton, 2010b; Dijkstra, Gielen, \& Melis, 1992). If images had been projected at a lower distance, the presence of the image-independent of the visual task performed-could have significantly changed the characteristics of postural sway (cf. Bonnet, Temprado, \& Berton, 2010b).

\section{Dependent Variables and Analyses}

The global measure of workload in the NASA-TLX assessed the subjective cognitive workload in each task (Hart \& Staveland, 1988).

The range (R), standard deviation (SD), and mean velocity (V) were used to analyze linear displacements of the COP, head, neck, and lower back in both anteroposterior (AP) and mediolateral (ML) axes (e.g., Era et al., 2006; Prieto, Myklebust, Hoffmann, Lovett, \& Myklebust, 1996). The variables were called $\mathrm{R}_{\mathrm{AP}}, \mathrm{R}_{\mathrm{ML}}, \mathrm{SD}_{\mathrm{AP}}, \mathrm{SD}_{\mathrm{ML}}, \mathrm{V}_{\mathrm{AP}}$, and $\mathrm{V}_{\mathrm{ML}}$. The angular displacement (yaw, pitch) of the head, neck and lower back were used to assess if the participants rotated their body segments during the tasks. The variables were called $\mathrm{R}_{\text {yaw }}, \mathrm{SD}_{\text {yaw }}, \mathrm{V}_{\text {yaw }}, \mathrm{R}_{\text {pitch }}, \mathrm{SD}_{\text {pitch }}$, and $\mathrm{V}_{\text {pitch. }}$. Changes in linear variables were used to discuss the so-called COP and body displacements or sways while changes in angular displacements were used to discuss goal-directed behaviors to perform the tasks. Hence, changes in angular displacement were not used to discuss an increase or a decrease in sway.

Usually in the literature reports, investigators seek to discover in which task the participants exhibit more or less COP and/or body sway. However, Kapteyn et al. (1983) 
suggested that the gold standard control task should lead to the minimum interindividual postural sway variability, not

265 to the minimum amount of postural sway. Therefore, to test our main hypothesis, the question was asked how to obtain interindividual postural sway variability for each participant in each trial?

In usual time-series, there is one value for each subject in

270 each trial. Hence, there is only one SD for each time-series, which one is calculated as the mean distance of data to the mean of the time-series $\left(\left(S D=\sqrt{\frac{\sum(x-\bar{x})^{2}}{n}}\right)\right)$. We needed to obtain a time-series in which each single value could design a variability and not a quantity of postural sway.

275 Our insight was to calculate the distance of each datum to the mean of the time-series with the formula $S D=\sqrt{(x-\bar{x})^{2}}$. In this way, each datum in the time-series showed interindividual variability (to the mean) that could be tested in statistical analyses. To be clear, we used all the

280 dependent variables mentioned earlier $\left(\mathrm{R}_{\mathrm{AP}}, \mathrm{R}_{\mathrm{ML}}, \mathrm{SD}_{\mathrm{AP}}\right.$, $\mathrm{SD}_{\mathrm{ML}}, \mathrm{V}_{\mathrm{AP}}, \mathrm{V}_{\mathrm{ML}}, \mathrm{R}_{\text {yaw }}, \mathrm{SD}_{\text {yaw }}, \mathrm{V}_{\text {yaw }}, \mathrm{R}_{\text {pitch }}, \mathrm{SD}_{\text {pitch }}$, and $\mathrm{V}_{\text {pitch }}$ for the head, neck, and lower back displacement and also $\mathrm{R}_{\mathrm{AP}}, \mathrm{R}_{\mathrm{ML}}, \mathrm{SD}_{\mathrm{AP}}, \mathrm{SD}_{\mathrm{ML}}, \mathrm{V}_{\mathrm{AP}}, \mathrm{V}_{\mathrm{ML}}, \mathrm{R}_{\text {yaw }}$, and $\mathrm{SD}_{\text {yaw }}$ for the COP displacement) but analyzed the distance to the

285 mean for each single variable. For these unconventional dependent variables chosen to test our main hypothesis, we only searched for effects of task between three tasks, that is, the stationary-gaze, white-panel, and free-viewing $12^{\circ}$ task. We did not analyze the effects of instruction or the

290 task by instruction interaction effects with these unconventional dependent variables because these results did not interest us (i.e., they could not test any of our hypotheses).

Many investigators in the literature reports assumed that the best control task should lead participants to

295 exhibit the lowest, or minimum, amount of postural sway (Glasauer, Schneider, Jahn, Strupp, \& Brandt, 2005; Laurens et al., 2010; Rougier \& Garin, 2006, Ustinova \& Perkins, 2011) and not lower interindividual postural sway variability. For this reason, we also ana-

300 lyzed in which task participants exhibited the lowest amount of COP and/or body sway. These analyses were only secondary, complementary, but did not test our second hypothesis. For these analyses, not only the effect of task but also the effect of instruction and the task by

305 instruction were detailed to test our last hypothesis (related to our second objective).

The mean duration and range of left/right and up/ down fixations were used to analyze characteristics of oculomotor behavior in the three free-viewing tasks

310 (e.g., Thibault, Delerue, Boucart, \& Tran, 2016). We were not only interested in showing that participants performed the task as requested but also in showing differences in oculomotor behaviors in the three free-viewing tasks performed either in steady or relaxed stances.
Hence, oculomotor behaviors were dependent variables and not independent variables.

The first five seconds of data from each trial were not analyzed to withdraw initial transient sway (e.g., Bonnet, Kinsella-Shaw et al., 2010; Kinsella-Shaw, Harrison, Colon-Semenza, \& Turvey, 2006). Preliminary Pearson correlation analyses between the time series and age, height, and weight each showed some significant relationships. Therefore, interindividual differences in age, height, and weight had an effect on the recorded behavioral variability. For this reason, the data were all normalized in terms of age, height, and weight in using the detrending normalization procedure recommended by O'Malley (1996). This detrending procedure was used to eliminate the influence of changes in age, height, and weight on the findings.

For the COP, body, and eye variables, the mean of the two trials per task was calculated. Preliminary analyses of the data showed normal distribution, homogeneity of variance, and no outlier. Hence, two-way analyses of variance (ANOVAs) were performed with task and instruction as independent variables $(p<.05)$. Additionally, post hoc Newman-Keuls tests compared the four visual tasks between each other in relaxed and steady stances separately $(p<.05)$.

\section{RESULTS}

\section{NASA-TLX Score}

The ANOVA showed significant effects of instruction, $F(1,15)=8.60, p<.05$, and of task, $F(3,45)=6.32$, $p<.05$. The visual tasks were considered as more difficult in steady stance $(10.60 \pm 3.45)$ than in relaxed stance $(8.88$ $\pm 3.00)$. The cognitive workload was significantly higher in the stationary-gaze task $(10.93 \pm 3.11)$ than in the three other tasks (white panel: $9.31 \pm 2.89$; free-viewing $12^{\circ}$ : $9.41 \pm 2.85$; free-viewing $\left.24^{\circ}: 9.31 \pm 2.62, p_{s}<.05\right)$ with no difference between these three latter tasks $\left(p_{s}>.33\right)$. The instruction by task interaction effect was not significant.

\section{COP and Body Displacements}

\section{Analyses of Interindividual Variability}

In summary, and for linear variables, there was significantly lower interindividual body linear variability in the free-viewing $12^{\circ}$ task than in the stationary-gaze task for four variables (head $\mathrm{SD}_{\mathrm{AP}}$; neck $\mathrm{SD}_{\mathrm{AP}}$; neck $\mathrm{V}_{\mathrm{AP}}$; neck $\mathrm{V}_{\mathrm{ML}}$; Figures 2A, 2B, 2C, and 2D). Additionally, the participants exhibited significantly higher interindividual body linear variability in the white-panel task than in the freeviewing $12^{\circ}$ task for two variables (neck $\mathrm{V}_{\mathrm{AP}}$; Neck $\mathrm{V}_{\mathrm{ML}}$; Figures 2C and 2D). Hence, there was significantly lower interindividual body linear variability in the free-viewing
315 

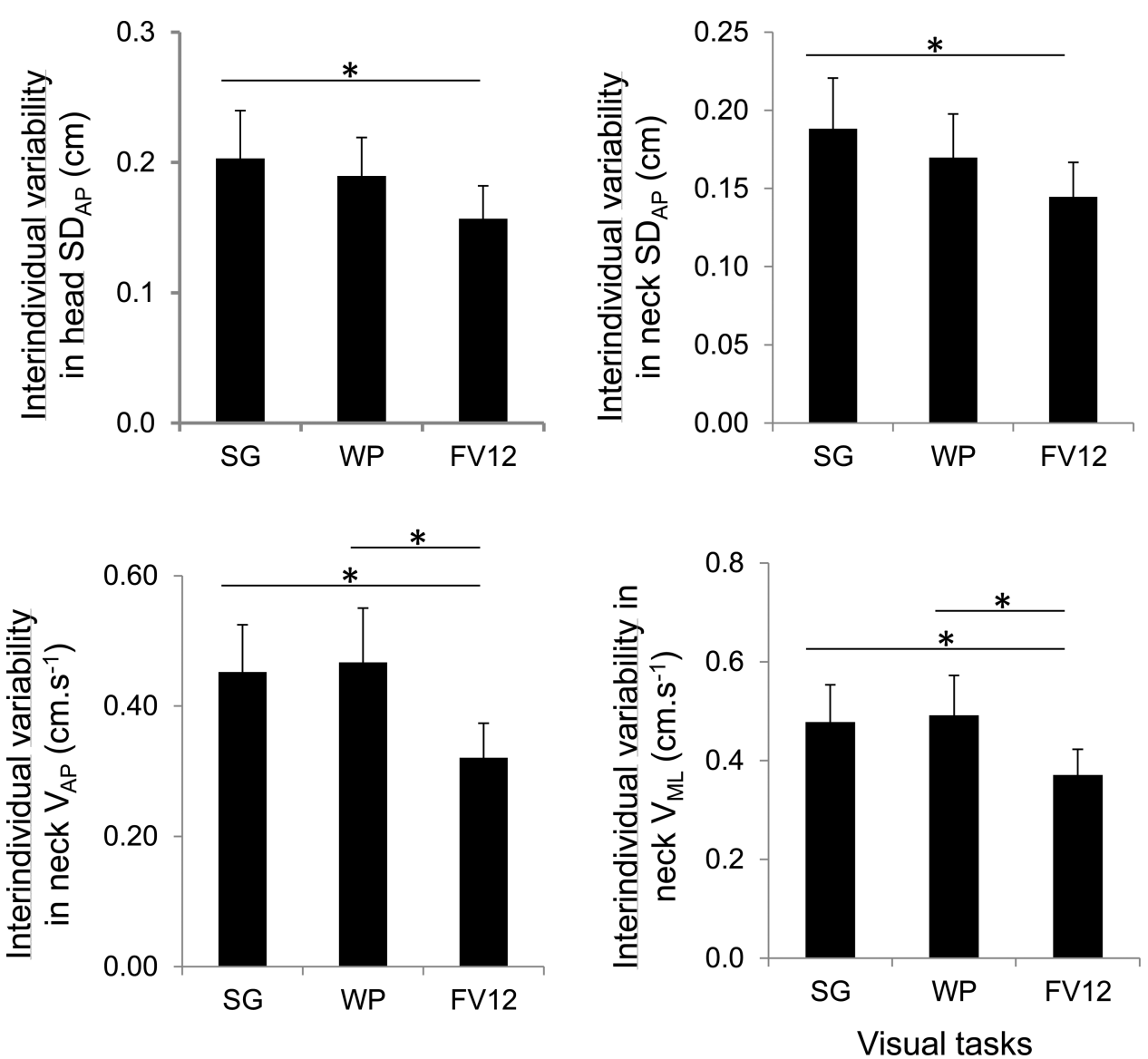

FIGURE 2. Significant effect of task $(p<.05)$ in the analysis of variance for the interindividual body variability in linear displacement. The interindividual variability for each subject was calculated in subtracting the mean value of the time-series with the value of each subject, taken in absolute value. The four significant effect of task were found for (A) the standard deviation of the head displacement (in $\mathrm{cm}$ ) in the anteroposterior axis (head $\left.\mathrm{SD}_{\mathrm{AP}}\right)$. (B) The $\mathrm{SD}$ of the neck displacement in the $\mathrm{AP}$ axis $\left(\right.$ neck $\left.\mathrm{SD}_{\mathrm{AP}}\right)$; the mean velocity $(\mathrm{V})$ of the neck displacement in the AP axis (neck $\mathrm{V}_{\mathrm{AP}}$ ); and (D) $\mathrm{V}$ of the neck displacement in the mediolateral axis (neck $\mathrm{V}_{\mathrm{ML}}$ ). In the stationary-gaze ( $\mathrm{SG}$ ) task, participants looked at a black dot ( $1^{\circ}$ of visual angle) projected on the wall in front of them. In the white-panel (WP) and free-viewing $12^{\circ}$ (FV12) tasks, participants could freely explore a white panel projected in a circle of $12^{\circ}$ or an image in a circle of $12^{\circ}$, respectively. The error bars represent the standard error of the mean. *Significant difference between two visual tasks $(p<.05)$.

$36512^{\circ}$ task than in both stationary-gaze and white-panel tasks. For angular variables, there was significantly lower interindividual variability in the stationary-gaze task than in the free-viewing $12^{\circ}$ task for both head $\mathrm{SD}_{\text {yaw }}$ and lower back $\mathrm{V}_{\text {pitch }}$ (Table 1). In contrast, there was significantly higher

370 interindividual body angular variability in the stationarygaze task than in the free-viewing $12^{\circ}$ task for both neck $\mathrm{V}_{\text {pitch }}$ and lower back $\mathrm{R}_{\text {pitch }}$ (Table 1). For all variables, interindividual body variability were not significantly different between both white-panel $\left(0.30^{\circ} \pm 0.04^{\circ}\right)$ and stationary-gaze task $\left(0.19^{\circ} \pm 0.03^{\circ}\right)$ but for the head $\mathrm{SD}_{\text {yaw }}$.

\section{Analyses of Conventional Linear and Angular Displacements}

Linear COP, head, neck, and lower back displacements. The effect of task was significant for two linear variables:
$\mathrm{COP} \mathrm{R}_{\mathrm{AP}}, F(3,45)=3.56, p<.05$, and neck $\mathrm{SD}_{\mathrm{AP}}, 380$ $F(3,45)=2.98, p<.05$. For COP $\mathrm{R}_{\mathrm{AP}}$, post hoc tests were not significant, both in steady and relaxed stances $\left(p_{s}>.18\right)$. However, the most important difference between conditions were found between the white-panel task and the free-viewing $24^{\circ}$ task. For $\mathrm{COP} \mathrm{SD}_{\mathrm{AP}}$, individuals exhibited significantly greater neck $\mathrm{SD}_{\mathrm{AP}}$ displacement in the white-panel task $(0.35 \pm 0.15 \mathrm{~cm})$ than in the free-viewing $24^{\circ}$ task $(0.30 \pm 0.15 \mathrm{~cm})$ only in steady stance $(p<.05)$ Hence, classical dependent variables of COP and body sway, representing the amount of sway, did not show any difference between the stationary-gaze task and the three other tasks. Significant effects of instruction are shown in Table 2. No instruction by task interaction effect was significant.

Angular head, neck, and lower back displacements. The effect of task was significant for angular variables at the head level only. It was significant for head $\mathrm{R}_{\mathrm{yaw}}, F(3,45)=3.61$, 
TABLE 1. Significant main effect of task in the analysis of variance for the head, neck, and lower back angular displacements in range, standard deviation, and velocity in the angular yaw and pitch directions.

\begin{tabular}{lcccc}
\hline \hline & & Tasks & & $\begin{array}{c}\text { Main effects } \\
\text { of task }\end{array}$ \\
\cline { 2 - 4 } $\begin{array}{l}\text { Dependent variables } \\
\text { (interindividual variability) }\end{array}$ & Stationary-gaze & White-panel & Free-viewing $12^{\circ}$ & $F(2,30)$ \\
\hline Head SDyaw & $0.19 \pm 0.03(*, \times)$ & $0.30 \pm 0.04(\times)$ & $0.32 \pm 0.05(*)$ & 4.49 \\
Neck Vpitch & $0.83 \pm 0.18\left(^{*}\right)$ & $0.95 \pm 0.19(+)$ & $0.60 \pm 0.12\left(^{*},+\right)$ & 8.52 \\
Lower-back Rpitch & $0.38 \pm 0.05\left(^{*}\right)$ & $0.40 \pm 0.06(+)$ & $0.32 \pm 0.05\left(*^{*},+\right)$ & 3.29 \\
Lower-back Vpitch & $1.36 \pm 0.20(*)$ & $1.22 \pm 0.16(+)$ & $1.73 \pm 0.17(*,+)$ & 6.02 \\
\hline
\end{tabular}

The values in the table show the distance to the mean for each variable, not the initially calculated range (R), standard deviation (SD) and velocity (V) fo each variable (see section 2.4 for more details). In the stationary-gaze task, participants had to stare at a black dot $\left(1^{\circ}\right.$ of visual angle) throughout the trial. In the white-panel and free-viewing $12^{\circ}$ tasks, they could freely look at a white panel or at an image projected within $12^{\circ}$ of visual angle. The data represent $M \pm S D$. Results of post hoc Newman-Keuls are shown by $*, \times,+{ }^{*}$ represents a significant difference between the free-viewing $12^{\circ}$ task and the stationary-gaze task; $\times$ represents a significant difference between the white-panel task and the stationary-gaze task; + represents a significant difference between the white-panel task and the free-viewing $12^{\circ}$ task. $p<.05$.

$p<.05$ (Figure 3A); head $\left.\mathrm{SD}_{\text {yaw }}, F(3,45)=4.43, p<.05\right)$; head $\mathrm{V}_{\text {yaw }}, F(3,45)=4.23, p<.05$; head $\mathrm{R}_{\text {pitch }}, F(3,45)=$ $4.19, p<.05$ (Figure 3B); and head $\mathrm{SD}_{\text {pitch }} F(3,45)=5.99$,

$400 p<.05$. Post hoc tests were only significant in relaxed stance and showed that the participants exhibited significantly lower head $\mathrm{R}_{\text {yaw }}$ (Figure $\left.3 \mathrm{~A}\right)$, lower head $\mathrm{SD}_{\text {yaw }}\left(0.76 \pm 0.28^{\circ}\right)$, and lower head $\mathrm{SD}_{\text {pitch }}\left(0.26 \pm 0.12^{\circ}\right)$ in the stationary-gaze task than in the three other tasks, that is, the white-panel (head

$405 \mathrm{R}_{\text {yaw }}$ : Figure $3 \mathrm{~A}$; head $\mathrm{SD}_{\text {yaw }}: 0.99 \pm 0.53^{\circ}$; head $\mathrm{SD}_{\text {pitch }}: 0.36$ \pm 0.21 ), free-viewing $12^{\circ}$ (head $\mathrm{R}_{\text {yaw }}$ : Figure $3 \mathrm{~A}$; head $\mathrm{SD}_{\text {yaw }}$ : $1.06 \pm 0.65^{\circ}$; head $\mathrm{SD}_{\text {pitch }}: 0.37 \pm 0.24$ ) and free-viewing $24^{\circ}$ (head $\mathrm{R}_{\text {yaw }}$ : Figure $3 \mathrm{~A}$; head $\mathrm{SD}_{\text {yaw }}$ : $1.18 \pm 0.65^{\circ}$; head
$\left.\mathrm{SD}_{\text {pitch }}: 0.42 \pm 0.26\right)$ tasks $(p<.05)$. Furthermore, the participants exhibited significantly lower head $\mathrm{R}_{\text {pitch }}$ in the stationarygaze task than in both free-viewing $12^{\circ}$ and $24^{\circ}$ tasks (Figure 3B; $p<.05$ ). Results for the effect of instruction are shown in Table 2 . No instruction by task interaction effect was significant.

\section{Oculomotor Behavior}

In each task, the participants performed the visual task as requested. In both stationary-gaze tasks (in steady and relaxes stances), they only looked at the stationary dot. Some fixations

TABLE 2 . Significant main effect of instruction in the ANOVA for the COP, head, and neck linear displacements (in $\mathrm{cm}$ ) both in range and in standard deviation in the AP and ML axes and in the angular yaw and pitch directions.

\begin{tabular}{|c|c|c|c|}
\hline \multirow[b]{2}{*}{ Dependent variables } & \multicolumn{2}{|c|}{ Instruction } & \multirow{2}{*}{$\begin{array}{c}\text { Main effects of } \\
\text { instruction, } F(1,15)\end{array}$} \\
\hline & Steady & Natural & \\
\hline COP R $\mathrm{ML}_{\mathrm{ML}}$ & $0.83 \pm 0.18$ & $1.28 \pm 0.79$ & 5.91 \\
\hline COP SD $\mathrm{SL}_{\mathrm{ML}}$ & $0.14 \pm 0.03$ & $0.22 \pm 0.13$ & 6.37 \\
\hline COP $\mathrm{R}_{\mathrm{AP}}$ & $1.67 \pm 0.33$ & $2.07 \pm 0.70$ & 6.71 \\
\hline Head $\mathrm{R}_{\mathrm{ML}}$ & $0.93 \pm 0.44$ & $1.42 \pm 0.93$ & 5.03 \\
\hline Head $\mathrm{SD}_{\mathrm{ML}}$ & $0.19 \pm 0.08$ & $0.28 \pm 0.17$ & 4.90 \\
\hline Head $R_{A P}$ & $1.72 \pm 0.89$ & $2.07 \pm 1.22$ & 5.84 \\
\hline Head $\mathrm{SD}_{\mathrm{AP}}$ & $0.37 \pm 0.19$ & $0.44 \pm 0.25$ & 5.27 \\
\hline Neck $R_{A P}$ & $1.52 \pm 0.80$ & $1.84 \pm 1.13$ & 5.21 \\
\hline Head $R_{\text {yaw }}$ & $3.59 \pm 1.05$ & $5.17 \pm 2.50$ & 7.82 \\
\hline Head $\mathrm{SD}_{\text {yaw }}$ & $0.70 \pm 0.19$ & $1.00 \pm 0.50$ & 6.91 \\
\hline Neck $R_{\text {yaw }}$ & $1.47 \pm 0.43$ & $1.98 \pm 0.82$ & 9.05 \\
\hline Neck $\mathrm{SD}_{\text {yaw }}$ & $0.27 \pm 0.09$ & $0.36 \pm 0.16$ & 7.98 \\
\hline Head $\mathrm{SD}_{\text {pitch }}$ & $0.27 \pm 0.06$ & $0.35 \pm 0.18$ & 5.14 \\
\hline Neck $R_{\text {pitch }}$ & $1.38 \pm 0.26$ & $1.70 \pm 0.47$ & 9.36 \\
\hline Neck $S_{\text {pitch }}$ & $0.27 \pm 0.05$ & $0.33 \pm 0.09$ & 7.70 \\
\hline
\end{tabular}

Note. In steady stance, participants had to stand as steady as possible. In relaxed stance, they stood in a relax way but were instructed to avoid making any body movement unrelated to the task performed. The data represent $M \pm S D . \mathrm{AP}=$ anteroposterior; $\mathrm{COP}=$ center of pressure; $\mathrm{ML}=$ mediolateral. $p<.05$. 


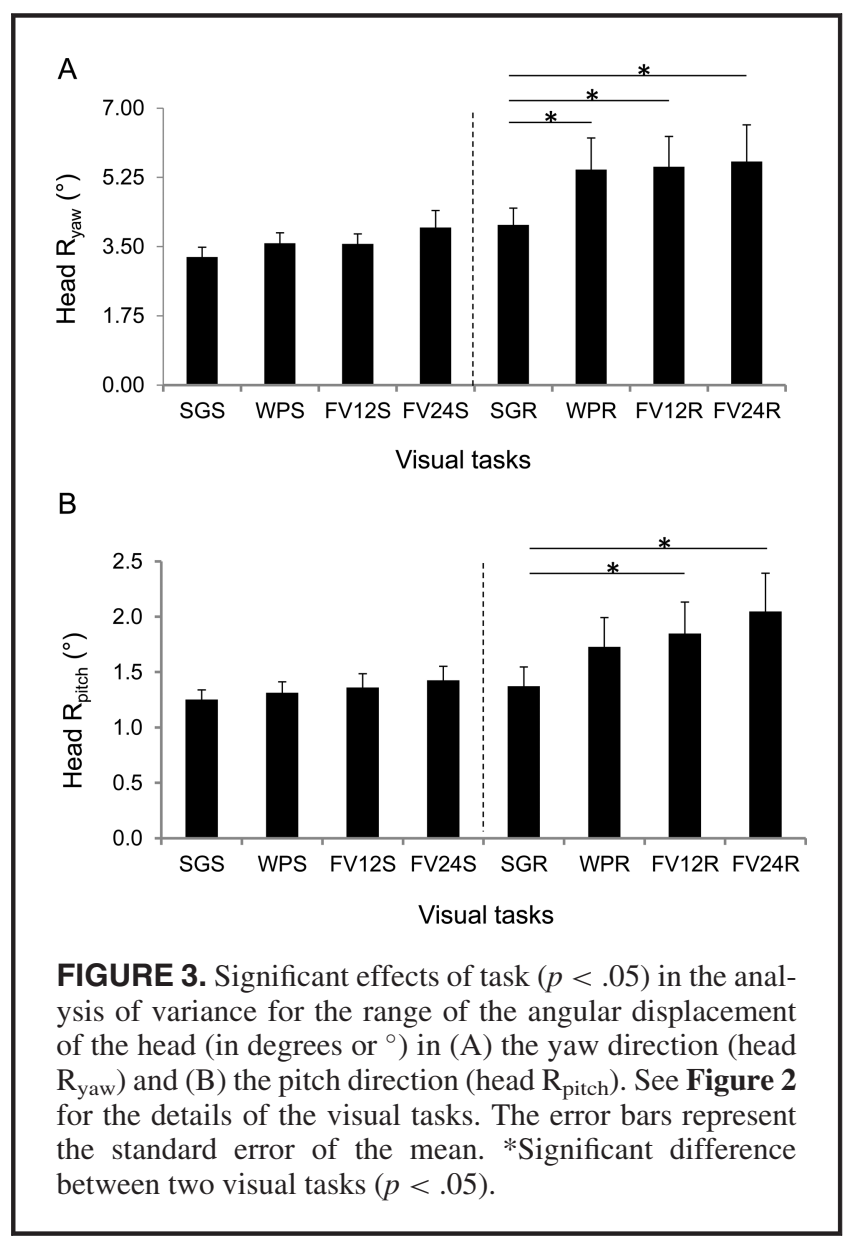

were performed away from the black dot (Figure 4A and 3B) but only a few ( $S D$ of left-right and up-down fixation $=0.72 \pm$ $0.35^{\circ}$ and $0.66 \pm 0.23^{\circ}$, respectively). In all other free-looking

440 tasks, the participants freely explored the images without looking outside of the circle (Figure 4A and 4B). The larger the circle was, the more extended their exploration of the image was (Figure 4A and 4B).

The effect of instruction was significant for the range of left445 right fixations, $F(1,15)=6.30, p<.05$, and for the mean duration of fixation, $F(1,15)=20.48, p<.05$. The participants performed shorter left/right visual exploration in steady stance $\left(9.75 \pm 1.17^{\circ}\right)$ than in relaxed stance $\left(10.76 \pm 1.18^{\circ}\right)$. The participants performed longer fixations in steady stance $(0.86 \pm$

$4500.24 \mathrm{~s})$ than in relaxed stance $(0.63 \pm 0.17 \mathrm{~s})$. Moreover, the instruction by task interaction effect was significant for the mean duration of fixation, $F(3,45)=4.66, p<.05$. The greater the participants explored, the shorter their mean duration of fixation was (stationary gaze: $1.66 \pm 0.65^{\circ}$; white panel: $0.54 \pm$

$4550.20^{\circ}$; free-viewing $12^{\circ}: 0.44 \pm 0.08^{\circ}$; free-viewing $24^{\circ}: 0.34$ $\left.\pm 0.05^{\circ}\right)$.

\section{DISCUSSION}

The present study first tested which of the white-panel, free-viewing $12^{\circ}$, and stationary-gaze tasks was the easiest

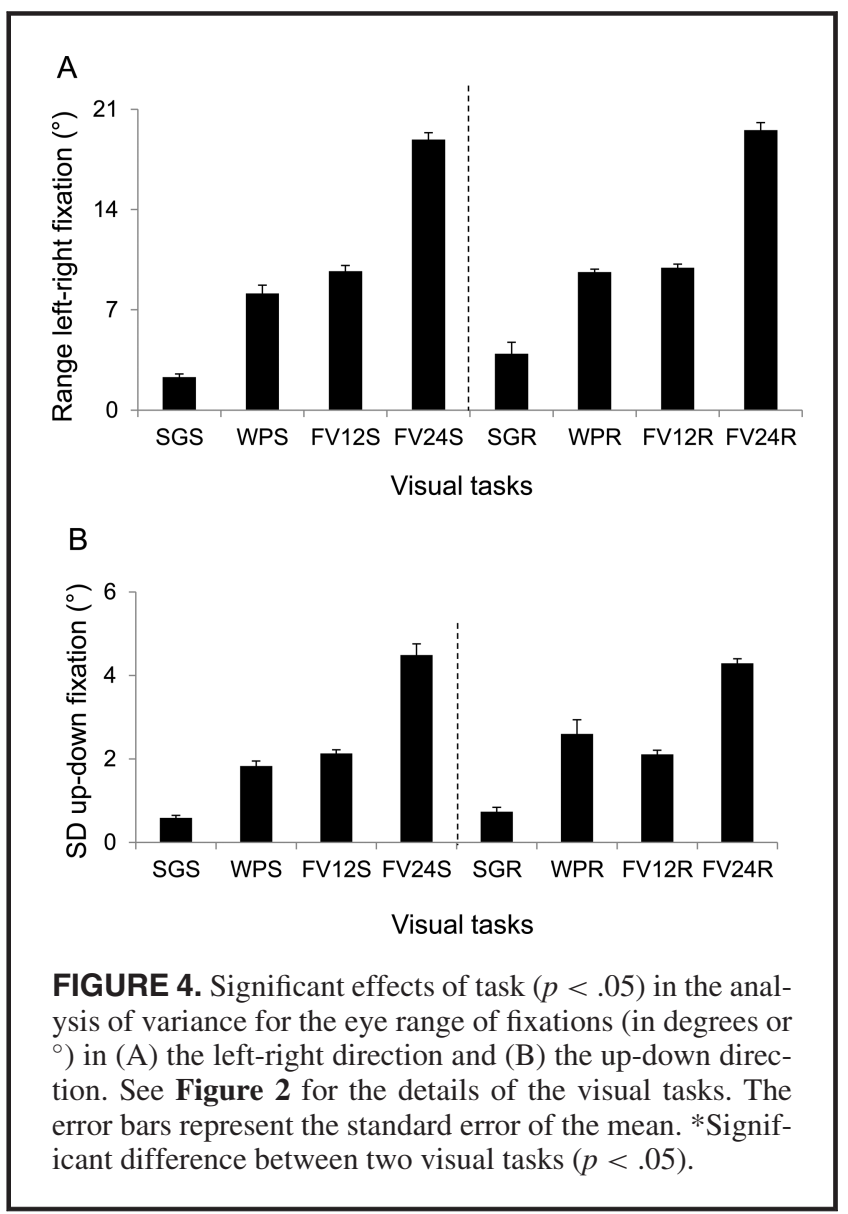

task (i.e., the task requiring the lowest amount of cognitive workload and of interindividual postural sway variability). The results showed that both white-panel and free-viewing $12^{\circ}$ tasks were cognitively less challenging than the stationary-gaze task. Moreover, there was significantly lower interindividual postural sway variability (COP or linear body displacements) in the free-viewing $12^{\circ}$ task than in both other tasks. Therefore, the free-viewing $12^{\circ}$ task could be assumed as significantly easier, less variable, than the stationary-gaze and white-panel tasks. Our second objective was to test if a free-viewing $24^{\circ}$ task could increase head and/or body segment rotation and therefore significantly increase COP and body displacement. Our study did not confirm this assumption because the participants mostly moved their eyes even in this free-viewing $24^{\circ}$ task.

\section{Definition and Role of the Control Task}

As explained by Fraizer and Mitra (2008), the control task should provide baseline results to understand the effects of other manipulations (i.e., all sorts of precise visual tasks in our manuscript). To be considered as control, the task should be the easiest task (Mitra, 2003) and therefore lead to the minimum amount of cognitive workload and interindividual body sway variability. It should lead to 
a minimum amount of interference (Swan et al., 2004). In 1983, a consortium of researchers decided that the station-

485 ary-gaze task should be considered as a gold control task both because all participants perform exactly the same task in which they are expected to engage a minimum of interindividual body sway variability (Kapteyn et al., 1983).

\section{Does the Stationary-Gaze Task Engage the Minimum \\ 490 Amount of Cognitive Workload and Interindividual Body Sway Variability?}

Our results did not confirm the intuitive consensus (Kapteyn et al., 1983) that the stationary-gaze task is the easiest task. Indeed, a first key finding is that the stationary-gaze

495 task was more cognitively demanding than the three other tasks, both in relaxed and steady stances $(p<.05)$. Therefore, the methodological requirement to keep the eyes stationary or free has important consequences on the cognitive demand. Our results confirmed former reports that this sta-

500 tionary-gaze task is constraining and may lead to higher cognitive workload (Ajrezzo et al., 2013; Ben Hamed et al., 2002) and higher attention (Legrand et al., 2013). It is a difficult task (Wade, 2010) and in our study, it was actually the hardest task. Even more interesting, our main analyses

505 showed the stationary-gaze task led to significantly larger interindividual postural sway variability (Figures $2 \mathrm{~A}, 2 \mathrm{~B}$, $2 \mathrm{C}$, and $2 \mathrm{D}$ ) than the free-viewing $12^{\circ}$ task. This is a second key finding. Our secondary analyses with many classical dependent variables also showed that the free-viewing $12^{\circ}$

510 task did not destabilize our group of healthy young individuals at all levels of the body (COP, head, neck, lower back), in all directions (AP, ML).

We assume that the larger interindividual postural sway variability in the stationary-gaze task may be explained by

515 the higher cognitive workload (i.e., higher cognitive interference) in the stationary-gaze task than in the free-viewing $12^{\circ}$ task. This higher interindividual postural sway variability in the stationary-gaze task may also be due to a higher variability in cognitive workload in that task. Indeed, some

520 participants could have thought a lot while other participants may not have done so in this stationary-gaze task (Fraizer \& Mitra, 2008). This high variability in psychological thoughts may be better controlled in the free-viewing $12^{\circ}$ task because participants are all engaged to perform an

525 exploratory task. Other criticisms of the stationary-gaze task exist in the literature reports. For example, the stationary-gaze task can quickly cause an attentional fatigue (Rougier \& Garin, 2006) or it can be a boring task (Barlow, 1952).

\section{Slight Angular Displacements in the Free-Looking Tasks Did Not Increase Postural Sway}

The two free-looking tasks (white-panel and free-viewing $12^{\circ}$ tasks) led to significantly greater amount of angular head displacement than the stationary-gaze task (Figures
$3 \mathrm{~A}$ and $3 \mathrm{~B}$ ), with almost no difference between these two free-looking tasks. These findings were unexpected because the targets were projected lower than $15^{\circ}$ of visual angle (Hallett, 1986). However, it should be noted that the differences with the stationary-gaze task were very small (differences in $\mathrm{R}_{\text {pitch }}$ and $\mathrm{R}_{\text {yaw }}<0.90^{\circ}$; differences in $\mathrm{SD}_{\text {pitch }}$ and $\mathrm{SD}_{\text {yaw }}<0.17^{\circ}$; Figures $3 \mathrm{~A}$ and $3 \mathrm{~B}$ ). Hence, these differences in task performance did not induce greater postural sway (COP, head, neck, lower back linear displacements) in the two free-looking tasks than in the stationary-gaze tasks.

\section{How to Design Future Studies Including Both Control and Experimental Tasks?}

Until this part of our manuscript, we only discussed that the control task should be the simplest task. Another important aspect in the definition of the control task is that it should be as similar to the experimental task(s) as possible but on one specific (tested) aspect. Hence, when different kinds of visual task are performed, the visual background should be identical, or equivalent, in both control and experimental tasks. We now discuss the most relevant control task in different paradigms of postural control.

If the experimental and control visual tasks both enables free eye motions on the same pictures, our study definitely shows that the ideal control task is a free-viewing task. For example, a free-viewing task could an ideal control task for another task in which participants are instructed to precisely detect something within the image (searching tasks; Shockley et al., 2003). Instead, the stationary-gaze task is definitely not a relevant control task for this experimental searching task because the stationary-gaze task leads to higher cognitive workload (cf. the NASA-TLX Score section) and interindividual postural sway variability (Figures $2 \mathrm{~A}, 2 \mathrm{~B}, 2 \mathrm{C}$, and 2D) than the best control free-viewing task. Moreover, the visual background is different in both tasks.

If the experimental visual task imposes specific oculomotor behaviors (e.g., gaze shifts on dots projected at a certain amplitude and frequency; Rougier \& Garin, 2007; or also in the task of counting the occurrence of letters in a text; Stoffregen et al., 2000), the most relevant control task may be the task of freely looking at a cubist transformation of these other experimental dots, or letters, or images (Kapoula, Adenis, Lê, Yang, \& Lipede, 2011). Indeed, the visual background would have the same number of pixels in both tasks and participants would be free to move their eyes in this control task. This free-viewing task would be better than the stationary-gaze task as a control task because it would avoid the cognitive workload to be biased.

The stationary-gaze task may be used adequately if participants stare at a black dot in all experimental conditions (e.g., Bonnet, Kinsella-Shaw et al., 2010). Here, the act of staring at a stationary target is a constant requirement and not an independent variable. However, one disadvantage of
535 540 
using the stationary-gaze task, we recall, is that it signifi-

590 cantly increases the cognitive workload of all tasks. If investigators are willing to perform the easiest possible control task, a solution could be to let participants freely look at small images projected in a circle of $12^{\circ}$ in all tasks, regardless of other manipulations superimposed on the

595 free-viewing task.

In our study, first the participants exhibited significantly lower COP, head, neck, and lower back displacements when they stood in steady stance than in relaxed stance (Table 2), as classically shown in the literature reports

600 (Bonnet, 2016; Zok, Mazzà, \& Cappozzo, 2008). Second, the steadiness requirement had problematic consequences on free oculomotor behaviors of the participants. Indeed, it significantly reduced the amplitude of the visual exploration in the left/right direction and increased the mean times

605 of fixation although the participants were entirely free to look at the image. Moreover, the steadiness requirement had the disadvantage to significantly increase the cognitive workload (cf. the NASA-TLX Score section), as suggested by Zok et al. (2008). Overall, therefore, we do not recom-

610 mend using this requirement in paradigms allowing free eye motions in one or several tasks.

\section{Additional Findings in the Free-Viewing $24^{\circ}$ Task}

The free-viewing $24^{\circ}$ task did not lead the participants to significantly increase their amount of body linear displace-

615 ment than the three other tasks both in relaxed and steady stances $(p=n s)$. It also did not lead the participants to significantly increase their amount of body angular displacement compared with the white-panel and free-viewing tasks both in relaxed and steady stances $(p=n s)$. These

620 findings were unexpected in the relaxed stance conditions because gaze shifts greater than $15^{\circ}$ were expected to require head motions (Hallett, 1986) and, as a consequence, increase postural sway. A first explanation is that the participants only extended their visual exploration until $19.2^{\circ}$ in

625 the free-viewing $24^{\circ}$ task, not $24^{\circ}$ (Figures $4 \mathrm{~A}$ and $4 \mathrm{~B}$ ). A second explanation is that eye rotations lower than $20^{\circ}$ are almost entirely performed by the eyes (Land \& Tatler, 2009). The lack of greater angular body rotations in the free-viewing $24^{\circ}$ may explain why this task did not lead to

630 significantly greater COP and/or body linear displacement than the other tasks. Overall, even this free-viewing $24^{\circ}$ task was easier than the stationary-gaze task, both in relaxed and steady stances.

\section{Limits and Conclusion}

635 The present study was performed with healthy young adults and the message therefore only concerned this population. In older adults or patients, we could assume that the cognitive workload would be significantly higher in the stationary-gaze task than in the

640 free-viewing $12^{\circ}$ task because the second task should still be less constraining, less tiring, and less frustrating. However, we cannot be sure that older adults or patients may exhibit significantly lower interindividual body linear variability or may sway less in a free-viewing $12^{\circ}$ task than in a stationary-gaze task. Indeed, some age-related or disease-related physiological disabilities may modify the way upright stance and visual explorations are controlled. For example, some of these individuals may rotate their head significantly more in the free-viewing $12^{\circ}$ task than in the stationary-gaze task-thus significantly increasing their postural sway-to better scan the image in the free-viewing task simply because of an age-related reduction in their field of view. For these individuals, a free-viewing $8^{\circ}$ or even stronger $4^{\circ}$ task may be more adapted control tasks to avoid this issue.

In summary, our study discussed the importance of the control task in paradigms of postural control. This task should be well chosen to avoid irrelevant interpretations of the data and to clearly detect and understand the presence and direction of significant findings. Our methodological study showed that the stationary-gaze task may not systematically provide the best baseline data to understand the effects of precise visual tasks on postural control. Instead, free-viewing tasks or cubist transformation of the experimental images (depending on the paradigm) may better provide relevant baseline data, in taking great care that the visual backgrounds are the same, or equivalent, in all visual tasks. At the practical level, the free-viewing task is also interesting as a control task because it is a more common, everyday life, activity than staring at a stationary dot. Hence, the comparison between the free-viewing task and the experimental task seems more relevant than the comparison between the stationary-gaze task and the experimental task.

\section{ACKNOWLEDGMENTS}

The authors thank Professor Normand Teasdale for his help to improve the manuscript.

\section{FUNDING}

The Polhemus system was funded by a research grant from the French National Research Agency (programme SHS2 ANR Lowvision).

\section{REFERENCES}

Ajrezo L., Wiener-Vacher, S., \& Bucci, M. P. (2013). Saccades improve postural control: A developmental study in normal children. PLoS ONE, 8, e81066. http://dx.doi.org/10.1371/journal.pone.0081066

Barlow, H. B. (1952). Eye movements during fixation. Journal of Physiology, 116, 290-306.

Ben Hamed, S., Duhamel, J. R., Bremmer, F., \& Graf, W. (2002). Visual receptive field modulation in the lateral intraparietal area 
during attentive fixation and free gaze. Cerebral Cortex, 12, 234-245.

Bonnet, C. T. (2016) Advantages and disadvantages of stiffness instructions when studying postural control. Gait \& Posture, 46, 208-220.

Bonnet, C. T., Kinsella-Shaw, J. M., Frank, T. D., Bubela, D., Harrison, S. J., \& Turvey, M. T. (2010). Deterministic and stochastic postural processes: Effects of task, environment, and age.

700 Journal of Motor Behavior, 42, 85-97.

Bonnet, C. T., Temprado, J. J., \& Berton, E. (2010). The effects of the proximity of an object on human stance. Gait \& Posture, $32,124-128$

Cegarra, J., \& Morgado, N. (2009). Étude des propriétés de la ver-

705 sion francophone du NASA-TLX. In B. Cahour, F. Anceaux, \&

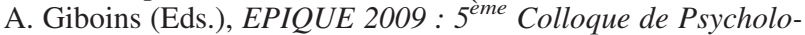
gie Ergonomique (pp. 233-239). Nice, France.

Dijkstra, T. M. H., Gielen, C. C. A. M., \& Melis, B. J. M. (1992). Postural responses to stationary and moving scenes as a func-

710 tion of distance to the scene. Human Movement Science, 11, 195-203.

Era, P., Sainio, P., Koskinen, S., Haavisto, P., Vaara, M., \& Aromaa, A. (2006). Postural balance in a random sample of 7,979 subjects aged 30 years and over. Gerontologty, 52, 204-213.

715 Fraizer, E. V., \& Mitra, S. (2008). Methodological and interpretive issues in posture-cognition dual-tasking in upright stance. Gait \& Posture, 27, 271-279.

Giveans, M. R., Yoshida, K., Bardy, B., Riley, M. \& Stoffregen, T. A. (2011). Postural sway and the amplitude of horizontal eye

720 movements. Ecological Psychology, 23, 247-266.

Glasauer, S., Schneider, E., Jahn, K., Strupp, M., \& Brandt, T. (2005). How the eyes move the body. Neurology, 65, 12921293.

Hallett, P. E. (1986). Eye movements. In K. R. Boff, L. Kaufman,

725 \& J. P. Thomas (Eds.), Handbook of human perception and performance (Vol. 1, Chapter 10). New York, NY: Wiley.

Hart, S. G. (2006). NASA-TLX index (NASA-TLX); 20 years later. Proceedings of the Human Factors and Ergonomics Society Annual Meeting, 50, 904-908.

730 Hart, S. G., \& Staveland, L. (1988). Development of the NASA task load index (TLX): Results of empirical and theoretical research. In P. A. Hancock \& N. Meshkati (Eds.), Human mental workload (pp. 139-183). Amsterdam, the Netherlands: North-Holland.

735 Kapoula, Z., Adenis, M. S., Lê, T. T., Yang, Q., \& Lipede, G. (2011). Pictorial deph increases body sway. Psychology of Aesthetics, Creativity, and the Arts, 5, 186-193.

Kapteyn, T. S., Bles, W., Njiokiktjien, C. J., Kodde, L., Massen, C. H., \& Mol, J. M. (1983). Standardization in platform stabil-

740 ometry being a part of posturography. Agressologie, 24, 321326.

Kinsella-Shaw, J. M., Harrison, S. J., Colon-Semenza, C., \& Turvey, M. T. (2006). Effects of visual environment on quiet standing by young and old adults. Journal of Motor Behavior, 38,

745 251-264.

Land, M. F., \& Tatler, B. W. (2009). Looking and acting. Vision and eye movements in natural behavior. Oxford, England: Oxford University Press.

Laurens, J., Awai, L., Bockisch, C. J., Hegermann, S., van Hedel, H. J.

750 A., Dietz, V., \& Straumann, D. (2010). Visual contribution to postural stability: Interaction between target fixation or tracking and static or dynamic large-field stimulus. Gait \& Posture, 31, 36-41.

Legrand, A., Mazars, K. D., Lazzareschi, J., Lemoine, C., Olivier, I., Barra, J., \& Bucci, M. P. (2013). Differing effects of prosac-

755 cades and antisaccades on postural stability. Experimental Brain Research, 3, 397-405. http://dx.doi.org/10.1007/s00221013-3519-z.
McIlroy, W. E., \& Maki, B. E. (1997). Preferred placement of the feet during quiet stance: Development of a standardized foot placement for balance testing. Clinical Biomechanics, 12, 6670.

Mihara, M., Miyai, I., Hatakenaka, M., Kubota, K., \& Sakoda, S. (2008). Role of the prefrontal cortex in human balance control. NeuroImage, 43, 329-336.

Mitra, S. (2003). Postural costs of suprapostural task load. Human Movement Science, 22, 253-270.

Mitra, S., Knight, A., \& Munn, A. (2013). Divergent effects of cognitive load on quiet stance and task-linked postural coordination. Journal of Experimental Psychology: Human Perception and Performance, 39, 323-328.

O’Malley, M. J. (1996). Normalization of temporal-distance parameters in pediatric gait. Journal of Biomechanics, 29, 619625.

Poulain, I., \& Giraudet, G. (2008). Age-related changes of visual contribution in posture control. Gait \& Posture, 27, $1-7$.

Prado, J. M., Duarte, M., \& Stoffregen, T. A. (2007). Postural sway during dual tasks in young and elderly adults. Gerontology, 53, 274-281.

Prieto, T. E., Myklebust, J. B., Hoffmann, R. G., Lovett, E. G., \& Myklebust, B. M. (1996). Measures of postural steadiness: Differences between healthy young and elderly adults. IEEE Transactions on Biomedical Engineering, 43, 956-966.

Rodrigues, S. T., Aguiar, S. A., Polastri, P. F., Godoi, D., Moraes, R., \& Barela, J. A. (2013). Effects of saccadic eye movements on postural control stabilization. Motriz Rio Claro, 19, 614-9.

Rougier, P., \& Garin, M. (2006). La réalization de mouvements de saccades oculaires affecte les stratégies de maintien de l'équilibre. Neurophysiologie Clinique, 36, 235-243.

Rougier, P., \& Garin, M. (2007). Performing saccadic eye movements or blinking improves postural control. Motor Control, 11, 213-223.

Shockley, K., Santana, M. V., \& Fowler, C. A. (2003). Mutual interpersonal postural constraints are involved in cooperative conversation. Journal of Experimental Psychology: Human Perception and Performance, 29, 326-332.

Stins, J. F. \& Beek, P. J. (2007). Effects of affective picture viewing on postural control. BMC Neuroscience, 8 , 83. http://dx.doi. org/10.1186/1471-2202-8-83.

Stoffregen, T. A., Bardy, B. G., Bonnet, C. T., Hove, P., \& Oullier, O. (2007). Postural sway and the frequency of horizontal eye movements. Motor Control, 11, 86-102.

Stoffregen, T. A., Bardy, B. G., Bonnet, C. T., \& Pagulayan, R. J. (2006). Postural stabilization of visually guided eye movements. Ecological Psychology, 18, 191-222.

Stoffregen, T. A., Hove, P., Bardy, B. G., Riley, M. A., \& Bonnet, C. T. (2007). Postural stabilization of perceptual but not cognitive performance. Journal of Motor Behavior, 39, $126-138$.

Stoffregen, T. A., Pagulayan, R. J., Bardy, B. G., \& Hettinger, L. J. (2000). Modulating postural control to facilitate visual performance. Human Movement Science, 19, 203-230.

Swan, L, Otani, H., Loubert, P. V., Sheffert, S. M., \& Dunbar, G. L. (2004). Improving balance by performing a secondary cognitive task. British Journal of Psychology, 95, 31-40.

Teasdale, N., Bard, C., LaRue, J., \& Fleury, M. (1993). On the cognitive penetrability of posture control. Experimental Aging Research, 19, 1-13.

Thibaut, M., Delerue, C., Boucart, M., \& Tran, T. H. C. (2016). Visual exploration of objects and scenes in people with macular degeneration. Journal Français d'Ophtalmologie, 39, 82-89. 
Ustinova, K. I., \& Perkins, J. (2011). Gaze and viewing angle influence visual stabilization of upright posture. Brain and Behavior, 1, 19-25.

Wade, N. J. (2010). Pioneers of eye movement research. I-Perception, 1, 33-68.

Woollacott, M., Shumway-Cook, A., \& Nashner, L. M. (1986).

830 Aging and posture control: Changes in sensory organization and muscular coordination. Journal of Aging Human Development, 23, 97-113.
Zok, M., Mazzà, C., \& Cappozzo, A. (2008). Should the instructions issued to the subject in traditional static posturography be standardized? Medical Engineering \& Physics, 30, 913-916.

Received March 14, 2016

Revised June 8, 2016

Accepted July 19, 2016 